\title{
META-ANALYSIS OF PLASMA INTERLEUKINE-6 LEVELS IN PATIENTS WITH DEPRESSIVE DISORDER
}

\author{
Gustav Bizik* \\ Center for Neuropsychiatric Research of Traumatic Stress, Department of Psychiatry, \\ $1^{\text {st }}$ Faculty of Medicine, Charles University, Prague, Czech Republic \\ Received March 15, 2010; accepted April 10, 2010
}

\begin{abstract}
Growing body of evidence suggests that inflammatory processes play an important role in the pathophysiology and the clinical course of depressive disorder, as well as several others major psychiatric and somatic conditions. Interleukin (IL6), one of the proinflammatory cytokines, has been extensively examined in a number of studies among depressed patients. To assess quantitatively the relationship between depression and IL-6, a systematic review of relevant literature published to October 2009 was performed and relevant data were meta-analysed using random-effects model. A positive association was found (standardized difference in means $=1.055, \mathrm{p}>0,001$ ), although a significant heterogeneity among studies $(\mathrm{Q}(15)=141, \mathrm{p}<0,001)$ points to relevance of further subgroup analyses.
\end{abstract}

Key words: Depression; IL-6; Meta-analysis

\section{INTRODUCTION}

Increasing body of research has been focused on implications of immune mechanisms in pathophysiological pathways leading to major somatic and psychiatric conditions. Importantly, proinflammatory processe frequently indexed using elevated levels of proinflammatory cytokines (such as interleukin IL-1 $\beta$, IL-6, interferon IFN- $\gamma$, tumor necrosis factor TNF- $\alpha$ ) have been reported in physical conditions such as in metabolic syndrome (Shelton \& Miller, 2010), atherosclerosis (Libby, Ridker, \& Maseri, 2002) and cancer (Hodge, Hurt, \& Farrar, 2005; Nilsson, Langley, \& Fidler, 2005) and psychiatric conditions such as depressive disorder (Howren, Lamkin, \& Suls, 2009), schizophrenia (Potvin et al., 2008) and posttraumatic stress disorder (PTSD) (Baker et al., 2001; Gill, Vythilingam, \& Page, 2008; Hoge et al., 2009; Maes et al., 1999; Song, Zhou, Guan, \& Wang, 2007). Although the question of directionality (from psychiatric condition towards inflammation or vice versa) is rather complex and remain open (Stewart, Rand, Muldoon, \& Kamarck, 2009), inflammatory processes have been proposed to explain in part significant association between psychiatric and somatic morbidity. Of note, proinflammatory cytokines, together with stress hormones, represent primary mediators of adversive health effects related to prolonged and dysregulated stress response in allostatic load model (Juster, McEwen, \& Lupien, 2009).

Due to its particular role in brain-body interactions, IL6 has been among the most extensively investigated proinflammatory molecule in a range of pre-clinical and clinical protocols. Its effects are multifaceted with an important role in the regulation of the innate immune reactions and complex interactions with stress system responses and neurotransmitter systems. In periphery, it is secreted both by activated macrophages and monocytes in response to immune challenge, adipose tissue (Tilg \& Moschen, 2006) and skeletal muscle (Steensberg et al., 2001). In central nervous system, the source of IL-6 is represented by activated microglia (Hanisch, 2002). It regulates acute phase protein production in liver (Castell et al., 1990) and stimulates proliferation and differentiation of B cells (Hodgkin et al., 1988). In the CNS, IL-6 exerts its multifold influence via IL-6 receptors expressed on neurons

*Correspondence to: Gustav Bizik, email: gustav.bizik@post.cz 
(Nelson, Ur, \& Gruol, 2002) and its interference with neurotransmitter systems (Shelton \& Miller, 2010). It mainly impacts on neural trophic processes (Monje, Toda, \& Palmer, 2003). Moreover, it is a potent stimulator of hypothalamo-pituitary-adrenal (HPA) axis (Lyson \& McCann, 1991; Mastorakos, Chrousos, \& Weber, 1993) and IL-6 levels are associated with acute exposition to physical and social stressors, as well as with conditions related to chronic stress (Lutgendorf et al., 1999). As reviewed by Shelton and Miller (Shelton \& Miller, 2010) several pathophysiologic pathways related to IL-6 were shown to have the potential to compromise serotoninergic, dopaminergic and glutamatergic circuitry.

Aforementioned mechanisms suggest possible biological underpinnings of the association between plasma or CSF IL-6 levels and different psychopathology. IL-6 levels were reported to be positively correlated with depression (Dentino et al., 1999; Lutgendorf, et al., 1999; Sjogren, Leanderson, Kristenson, \& Ernerudh, 2006), hostility (Sjogren, et al., 2006; Suarez, 2003), hopelessness and vital exhaustion (Sjogren, et al., 2006). On the contrary, IL-6 levels were found to be negatively correlated with coping and selfesteem (Sjogren, et al., 2006). Consistently, number of individual studies (see Fig. 1) documented the relationship between IL-6 levels and depressive disorder with the majority of them reporting a significant elevations of IL-6 plasma levels in depressive patients compared to normal control population. Using a metaanalytic approach, the relationship will be assessed quantitatively in this article.

\section{METHODS}

English language literature published between January 1967 and October 2009 and reporting the relationship between IL-6 levels and depression was reviewed using PubMed electronic database. The search was performed with following combinations between keywords: interleukin 6, IL-6 combined with depression and depressive. Inclusion criteria were set to select crosssectional studies assessing either plasma or serum unstimulated IL-6 concentrations in both depressed inpatients and outpatients, aged between 18 and 65 years, both drug naive and under psychiatric treatment and free of somatic comorbidity (such as CAD-related disease, cancer, renal disease). Studies were included if depressive symptoms were assessed using standardised clinical interviews according to DSM III-R or DSM IV criteria and if healthy subjects were used as control group. Only studies providing sufficient information to calculate effects sizes (i.e. number of participants in patient and control groups and either the mean value of IL-6 level and standard deviation, or the difference of the means of both group with corresponding p-value) were selected. In the majority of studies sampling times were between 7-9 a.m.; in cases of serial sampling the overall mean value was used.

Statistical analyses were performed using The Comprehensive Meta-Analysis software package version 2.0. Aggregate effect size was calculated based on random-effects models assuming a distribution of effect sizes across the studies and estimating both the within- and between-study variations. Effect size was considered positive when values of IL-6 levels patients groups were higher compared to those in healthy control groups. To assess the heterogeneity among study effect sizes, Q statistic was calculated. Finally, a fail-safe N was computed and a funnel plot was constructed to address the problem of publication bias.

\section{RESULTS}

PubMed search provided 529 potentially relevant articles. 514 did not met inclusion criteria (review articles, editorial letters, duplicate studies and papers not containing complete data) and 16 were submitted for further analysis.

Results presented in Figure 1 shows the forest plot of the standardized differences in means (SMD) of IL-6 levels in depression group versus healthy control group. Meta-analysis using random effect model revealed a significant difference in pooled effects sizes between both groups $(\mathrm{SMD}=1.055, \mathrm{p}>0,001)$. A significant heterogeneity among effect sizes was found $(\mathrm{Q}(15)=141, \mathrm{p}<0,001)$.

Results presented in Figure 2 displays the funnel plot for articles included in the meta-analysis. The asymmetrical distribution of studies distribution suggests a possible publication bias, however corresponding fail-safe $\mathrm{N}$ was substantial, indicating that 582 missing studies with null results would be necessary to make the calculated aggregated effect size non-significant.

\section{DISCUSSION}

Results of the meta-analysis confirm a positive association between IL-6 levels and depression in both inpatients and outpatient adult population (free of major somatic comorbidity). The findings are consistent with the results of previous meta-analytic studies reporting a relationship between depression and complex alterations in cellular immunity (Herbert \& Cohen, 


\begin{tabular}{|c|c|c|c|c|c|c|c|c|c|c|c|c|c|}
\hline \multirow[t]{2}{*}{ Model } & \multirow[t]{2}{*}{ Study name } & \multicolumn{7}{|c|}{ Statistics for each study } & \multicolumn{5}{|c|}{ Std diff in means and $95 \% \mathrm{Cl}$} \\
\hline & & $\begin{array}{l}\text { Std diff in } \\
\text { means }\end{array}$ & $\begin{array}{c}\text { Standard } \\
\text { error }\end{array}$ & Variance & Lower limit & Upper limit & $Z$ Value & p.Value & $\cdot 5,00$ & $\cdot 2,50$ & 0,00 & 2,50 & 5,00 \\
\hline & Alesci, 2005 & 1.729 & 0.553 & 0,305 & 0,647 & 2,812 & 3,130 & 0.002 & & & & & \\
\hline & Dhabhar, 2009 & 1.599 & 0,479 & 0,230 & 0,659 & 2,538 & 3,335 & 0.001 & & & & & \\
\hline & Eskandari, 2007 & 1.898 & 0,434 & 0,188 & 1,047 & 2,749 & 4,373 & 0,000 & & & & & \\
\hline & Kagaya, 2001 & .0,139 & 0.409 & 0,167 & .0 .941 & 0,662 & $.0,341$ & 0,733 & & & & & \\
\hline & Kahl, 2005 & 0,548 & 0,331 & 0,110 & $.0,101$ & 1,196 & 1,655 & 0,098 & & & - & & \\
\hline & Kubera, 2000 & 0.957 & 0,485 & 0.235 & 0,006 & 1,908 & 1,973 & 0.048 & & & & & \\
\hline & Leo, 2006 & 1,190 & 0,226 & 0,051 & 0,746 & 1,633 & 5,259 & 0,000 & & & $\rightarrow$ & & \\
\hline & Maes, 1995 & 3,525 & 0.325 & 0,105 & 2,889 & 4,162 & 10,855 & 0,000 & & & & & \\
\hline & Maes, 1997 & 0,766 & 0,338 & 0,114 & 0,104 & 1.428 & 2,269 & 0.023 & & & & & \\
\hline & Mikova, 2001 & 0,250 & 0,321 & 0,103 & $.0,379$ & 0,880 & 0.779 & 0.436 & & & — & & \\
\hline & Motivala, 2005 & 0.848 & 0,332 & 0,110 & 0,198 & 1,498 & 2,556 & 0.011 & & & $\longrightarrow$ & & \\
\hline & Pike, 2006 & 0,741 & 0,292 & 0,085 & 0,168 & 1,314 & 2,535 & 0.011 & & & $\longrightarrow$ & & \\
\hline & Rief, 2001 & 0,131 & 0.234 & 0,055 & $.0,329$ & 0,590 & 0,558 & 0,577 & & & & & \\
\hline & Sluzewska, 1996 & 1,970 & 0,343 & 0,117 & 1,298 & 2,641 & 5,749 & 0.000 & & & & & \\
\hline & Song. 1998 & 1,078 & 0.517 & 0,267 & 0,065 & 2,091 & 2,085 & 0.037 & & & & & \\
\hline & Vaccarino, 2008 & 0,143 & 0,127 & 0.016 & $.0,105$ & 0,391 & 1,127 & 0.260 & & & + & & \\
\hline Random & & 1,055 & 0,236 & 0,056 & 0,592 & 1,519 & 4,463 & 0,000 & & & + & & \\
\hline
\end{tabular}

Figure 1. Forest plot of the standardized differences in means (SMD) of IL-6 levels in depression group versus healthy control group

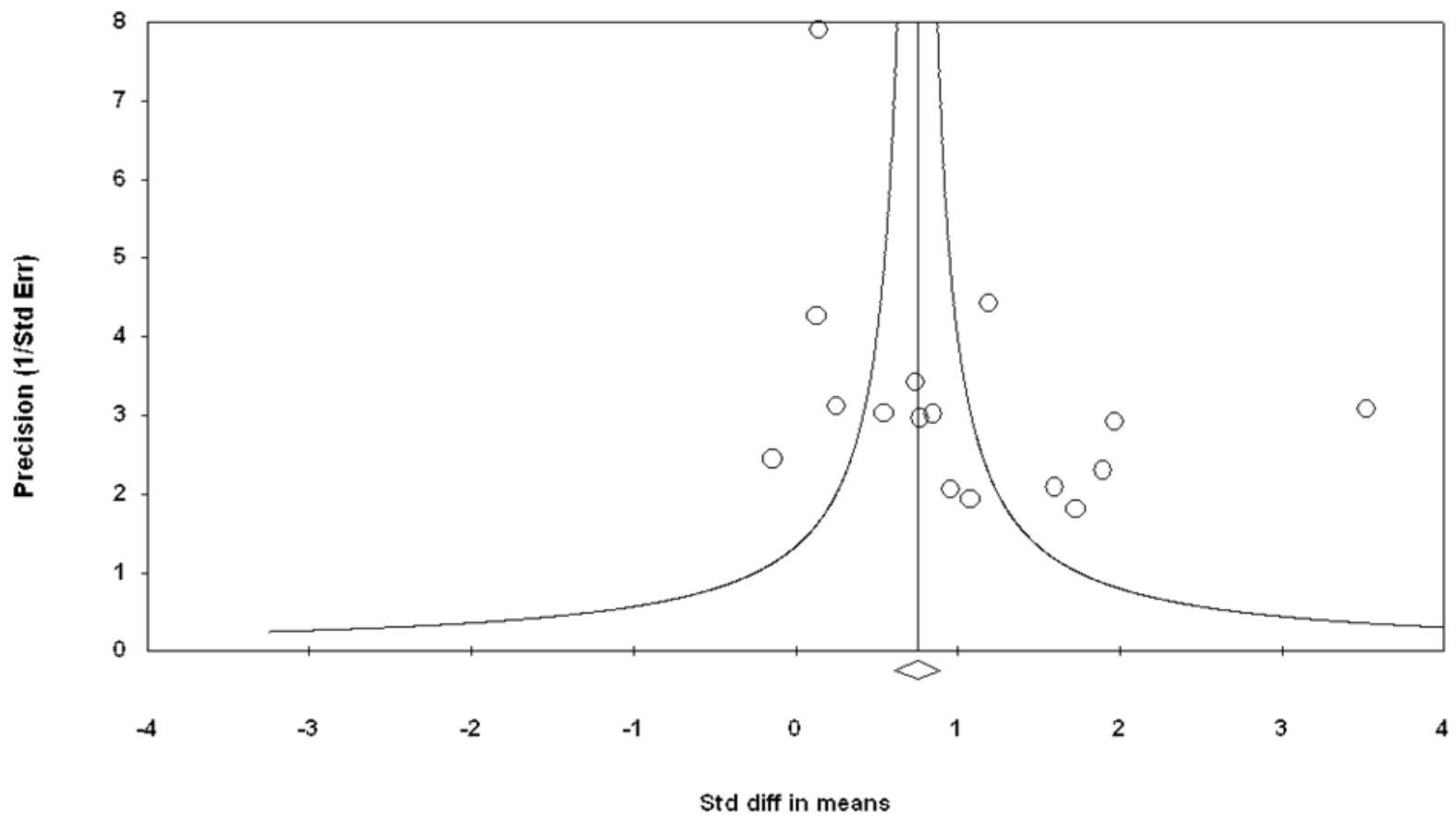

Figure 2. Funnel plot for articles included in meta-analysis

1993; Zorrilla et al., 2001) and proinflammatory cytokines (Howren, et al., 2009; Kuo et al., 2005; Zorri1la, et al., 2001), with 2 articles assessing directly IL-6 levels (Howren, et al., 2009; Zorrilla, et al., 2001).

The interpretation of the results is limited due to a significant heterogeneity among included studies suggesting an important role of biological, clinical and technical confounders. The most important biological factors include age, sex and BMI. IL-6 levels were shown to augment with age (Cohen, Pieper, Harris, Rao, $\&$ Currie, 1997) and, importantly, the association between IL-6 and depression was weakened with age in the meta-analytic study by Howren and coworkers (Howren, et al., 2009). The IL-6 levels were also found to fluctuate during menstrual cycle (Angstwurm, Gartner, \& Ziegler-Heitbrock, 1997) and to be modulated by oral contraceptive use (Salkeld, MacAulay, Ball, \& Cannon, 2001). Additionally, as 
already noted, adipose tissue represents an important source of IL-6 (Tilg \& Moschen, 2006) and, consistently, adjusting for BMI in Howren and colleagues'analysis influenced substantially the final aggregated effect size (Howren, et al., 2009). Besides, treatment-related factors, such as antidepressant medication, influence serum levels of IL-6, as shown by Janssen and coworkers (Janssen, Caniato, Verster, \& Baune, 2010). Finally, a source of observed heterogeneity could be linked with limited comparability between the essays performed by different operators or laboratories (Noble et al., 2008).

\section{CONCLUSION}

The findings support the relevance of inflammatory response system activation in the pathophysiology and clinical course of depressive disorder among adult patients. Further longitudinal studies are required to bring insights as for the directionality of these interrelated processes.

\section{Acknowledgement}

This work was supported by research grant MSM0021620849 and research project of Center for Neuropsychiatric Research of Traumatic Stress $1 \mathrm{M} 06039$ by Czech Ministry of Education.

\section{REFERENCES}

Alesci, S., Martinez, P. E., Kelkar, S., Ilias, I., Ronsaville, D. S., Listwak, S. J., et al. (2005). Major depression is associated with significant diurnal elevations in plasma interleukin-6 levels, a shift of its circadian rhythm, and loss of physiological complexity in its secretion: clinical implications. Journal of Clinical Endocrinology \& Metabolism, 90, 2522-2530.

Angstwurm, M. W., Gartner, R., \& Ziegler-Heitbrock, H. W. (1997). Cyclic plasma IL-6 levels during normal menstrual cycle. Cytokine, 9, 370-374.

Baker, D. G., Ekhator, N. N., Kasckow, J. W., Hill, K. K., Zoumakis, E., Dashevsky, B. A., et al. (2001). Plasma and cerebrospinal fluid interleukin-6 concentrations in posttraumatic stress disorder. Neuroimmunomodulation, 9, 209-217.

Castell, J. V., Gomez-Lechon, M. J., David, M., Fabra, R., Trullenque, R., \& Heinrich, P. C. (1990). Acute-phase response of human hepatoc' $=$ ytes: regulation of acute-phase protein synthesis by interleukin-6. Hepatology, 12, 11791186.

Cohen, H. J., Pieper, C. F., Harris, T., Rao, K. M., \& Currie, M. S. (1997). The association of plasma IL-6 levels with functional disability in community-dwelling elderly. The Journals of Gerontology. Series A, Biological Sciences and Medical Sciences, 52, M201-208.

Dentino, A. N., Pieper, C. F., Rao, M. K., Currie, M. S., Harris, T., Blazer, D. G., et al. (1999). Association of interleukin- 6 and other biologic variables with depression in older people living in the community. Journal of the American Geriatrics Society, 47, 6-11.

Dhabhar, F. S., Burke, H. M., Epel, E. S., Mellon, S. H., Rosser, R., Reus, V. I., et al. (2009). Low serum IL-10 concentrations and loss of regulatory association between IL-6 and IL-10 in adults with major depression. Journal of Psychiatric Research, 43, 962-969.

Eskandari, F., Martinez, P. E., Torvik, S., Phillips, T. M., Sternberg, E. M., Mistry, S., et al. (2007). Low bone mass in premenopausal women with depression. Archives of Internal Medicine, 167, 2329-2336.

Gill, J., Vythilingam, M., \& Page, G. G. (2008). Low cortisol, high DHEA, and high levels of stimulated TNF-alpha, and IL6 in women with PTSD. Journal of Traumatic Stress, 21, 530539.

Hanisch, U. K. (2002). Microglia as a source and target of cytokines. Glia, 40, 140-155.

Herbert, T. B., \& Cohen, S. (1993). Depression and immunity: a meta-analytic review. Psychological Bulletin, 113, 472-486.

Hodge, D. R., Hurt, E. M., \& Farrar, W. L. (2005). The role of IL-6 and STAT3 in inflammation and cancer. European Journal of Cancer, 41, 2502-2512.

Hodgkin, P. D., Bond, M. W., O'Garra, A., Frank, G., Lee, F., Coffman, R. L., et al. (1988). Identification of IL-6 as a T cellderived factor that enhances the proliferative response of thymocytes to IL-4 and phorbol myristate acetate. Journal of Immunology, 141, 151-157.

Hoge, E. A., Brandstetter, K., Moshier, S., Pollack, M. H., Wong, K. K., \& Simon, N. M. (2009). Broad spectrum of cytokine abnormalities in panic disorder and posttraumatic stress disorder. Depression and Anxiety, 26, 447-455.

Howren, M. B., Lamkin, D. M., \& Suls, J. (2009). Associations of depression with C-reactive protein, IL-1, and IL-6: a meta-analysis. Psychosomatic Medicine, 71, 171-186. Janssen, D. G., Caniato, R. N., Verster, J. C., \& Baune, B. T. (2010). A psychoneuroimmunological review on cytokines involved in antidepressant treatment response. Human Psychopharmacology, 25, 201-215.

Juster, R. P., McEwen, B. S., \& Lupien, S. J. (2009). Allostatic load biomarkers of chronic stress and impact on health and cognition. Neuroscience and Biobehavioral Reviews (in press),

doi:10.1016/j.neubiorev.2009.10.002

Kagaya, A., Kugaya, A., Takebayashi, M., Fukue-Saeki, M., Saeki, T., Yamawaki, S., et al. (2001). Plasma concentrations of interleukin-1beta, interleukin-6, soluble interleukin-2 receptor and tumor necrosis factor alpha of depressed patients in Japan. Neuropsychobiology, 43, 59-62.

Kahl, K. G., Bester, M., Greggersen, W., Rudolf, S., Dibbelt, L., Stoeckelhuber, B. M., et al. (2005). Visceral fat deposition and insulin sensitivity in depressed women with and without comorbid borderline personality disorder. Psychosomatic Medicine, 67, 407-412.

Kubera, M., Kenis, G., Bosmans, E., Zieba, A., Dudek, D., Nowak, G., et al. (2000). Plasma levels of interleukin-6, interleukin-10, and interleukin-1 receptor antagonist in depression: comparison between the acute state and after remission. Polish Journal of Pharmacology, 52, 237-241.

Kuo, H. K., Yen, C. J., Chang, C. H., Kuo, C. K., Chen, J. H., \& Sorond, F. (2005). Relation of C-reactive protein to stroke, cognitive disorders, and depression in the general population: systematic review and meta-analysis. Lancet Neurology, 4, 
371-380.

Leo, R., Di Lorenzo, G., Tesauro, M., Razzini, C., Forleo, G. B., Chiricolo, G., et al. (2006). Association between enhanced soluble CD40 ligand and proinflammatory and prothrombotic states in major depressive disorder: pilot observations on the effects of selective serotonin reuptake inhibitor therapy. Journal of Clinical Psychiatry, 67, 1760-1766.

Libby, P., Ridker, P. M., \& Maseri, A. (2002). Inflammation and atherosclerosis. Circulation, 105, 1135-1143.

Lutgendorf, S. K., Garand, L., Buckwalter, K. C., Reimer, T. T., Hong, S. Y., \& Lubaroff, D. M. (1999). Life stress, mood disturbance, and elevated interleukin-6 in healthy older women. The Journals of Gerontology. Series A, Biological Sciences and Medical Sciences, 54, M434-439.

Lyson, K., \& McCann, S. M. (1991). The effect of interleukin-6 on pituitary hormone release in vivo and in vitro. Neuroendocrinology, 54, 262-266.

Maes, M., Bosmans, E., De Jongh, R., Kenis, G., Vandoolaeghe, E., \& Neels, H. (1997). Increased serum IL-6 and IL-1 receptor antagonist concentrations in major depression and treatment resistant depression. Cytokine, 9, 853-858.

Maes, M., Lin, A. H., Delmeire, L., Van Gastel, A., Kenis, G., De Jongh, R., et al. (1999). Elevated serum interleukin-6 (IL6) and IL-6 receptor concentrations in posttraumatic stress disorder following accidental man-made traumatic events. Biological Psychiatry, 45, 833-839.

Maes, M., Meltzer, H. Y., Bosmans, E., Bergmans, R., Vandoolaeghe, E., Ranjan, R., et al. (1995). Increased plasma concentrations of interleukin-6, soluble interleukin-6, soluble interleukin-2 and transferrin receptor in major depression. Journal of Affective Disorders, 34, 301-309.

Mastorakos, G., Chrousos, G. P., \& Weber, J. S. (1993). Recombinant interleukin-6 activates the hypothalamicpituitary-adrenal axis in humans. Journal of Clinical Endocrinology \& Metabolism, 77, 1690-1694.

Mikova, O., Yakimova, R., Bosmans, E., Kenis, G., \& Maes, M. (2001). Increased serum tumor necrosis factor alpha concentrations in major depression and multiple sclerosis. European Neuropsychopharmacology, 11, 203-208.

Monje, M. L., Toda, H., \& Palmer, T. D. (2003). Inflammatory blockade restores adult hippocampal neurogenesis. Science, 302, 1760-1765.

Motivala, S. J., Sarfatti, A., Olmos, L., \& Irwin, M. R. (2005). Inflammatory markers and sleep disturbance in major depression. Psychosomatic Medicine, 67, 187-194.

Nelson, T. E., Ur, C. L., \& Gruol, D. L. (2002). Chronic interleukin-6 exposure alters electrophysiological properties and calcium signaling in developing cerebellar purkinje neurons in culture. Journal of Neurophysiology, 88, 475-486.

Nilsson, M. B., Langley, R. R., \& Fidler, I. J. (2005). Interleukin-6, secreted by human ovarian carcinoma cells, is a potent proangiogenic cytokine. Cancer Research, 65, 1079410800.

Noble, J. E., Wang, L., Cerasoli, E., Knight, A. E., Porter, R. A., Gray, E., et al. (2008). An international comparability study to determine the sources of uncertainty associated with a non-competitive sandwich fluorescent ELISA. Clinical Chemistry and Laboratory Medicine, 46, 1033-1045.

Pike, J. L., \& Irwin, M. R. (2006). Dissociation of inflammatory markers and natural killer cell activity in major depressive disorder. Brain, Behavior, and Immunity, 20, 169174.

Potvin, S., Stip, E., Sepehry, A. A., Gendron, A., Bah, R., \& Kouassi, E. (2008). Inflammatory cytokine alterations in schizophrenia: a systematic quantitative review. Biological Psychiatry, 63, 801-808.

Rief, W., Pilger, F., Ihle, D., Bosmans, E., Egyed, B., \& Maes, M. (2001). Immunological differences between patients with major depression and somatization syndrome. Psychiatry Research, 105, 165-174.

Salkeld, B. D., MacAulay, J. C., Ball, R. W., \& Cannon, J. G. (2001). Modulation of body temperature, interleukin-6 and leptin by oral contraceptive use. Neuroimmunomodulation, 9, 319-325.

Shelton, R. C., \& Miller, A. H. (2010). Eating ourselves to death and despair: The contribution of adiposity and inflammation to depression. Progress in Neurobiology doi:10.1016/j.pneurobio.2010.04.004 (in press).

Sjogren, E., Leanderson, P., Kristenson, M., \& Ernerudh, J. (2006). Interleukin-6 levels in relation to psychosocial factors: studies on serum, saliva, and in vitro production by blood mononuclear cells. Brain, Behavior, and Immunity, 20, 270278.

Sluzewska, A., Rybakowski, J., Bosmans, E., Sobieska, M., Berghmans, R., Maes, M., et al. (1996). Indicators of immune activation in major depression. Psychiatry Research, 64, 161167.

Song, C., Lin, A., Bonaccorso, S., Heide, C., Verkerk, R., Kenis, G., et al. (1998). The inflammatory response system and the availability of plasma tryptophan in patients with primary sleep disorders and major depression. Journal of Affective Disorders, 49, 211-219.

Song, Y., Zhou, D., Guan, Z., \& Wang, X. (2007). Disturbance of serum interleukin-2 and interleukin- 8 levels in posttraumatic and non-posttraumatic stress disorder earthquake survivors in northern China. Neuroimmunomodulation, 14, 248-254.

Steensberg, A., Febbraio, M. A., Osada, T., Schjerling, P., van Hall, G., Saltin, B., et al. (2001). Interleukin-6 production in contracting human skeletal muscle is influenced by preexercise muscle glycogen content. Journal of Physiology, 537, 633-639.

Stewart, J. C., Rand, K. L., Muldoon, M. F., \& Kamarck, T. W. (2009). A prospective evaluation of the directionality of the depression-inflammation relationship. Brain, Behavior, and Immunity, 23, 936-944.

Suarez, E. C. (2003). Joint effect of hostility and severity of depressive symptoms on plasma interleukin-6 concentration. Psychosomatic Medicine, 65, 523-527.

Tilg, H., \& Moschen, A. R. (2006). Adipocytokines: mediators linking adipose tissue, inflammation and immunity. Nature Reviews. Immunology, 6, 772-783.

Vaccarino, V., Brennan, M. L., Miller, A. H., Bremner, J. D., Ritchie, J. C., Lindau, F., et al. (2008). Association of major depressive disorder with serum myeloperoxidase and other markers of inflammation: a twin study. Biological Psychiatry, 64, 476-483.

Zorrilla, E. P., Luborsky, L., McKay, J. R., Rosenthal, R., Houldin, A., Tax, A., et al. (2001). The relationship of depression and stressors to immunological assays: a metaanalytic review. Brain, Behavior, and Immunity, 15, 199-226. 